BMJ Open Sport \& Exercise Medicine

\title{
Fall-related accidents among hikers in the Austrian Alps: a 9-year retrospective study
}

Martin Faulhaber, ${ }^{1}$ Elena Pocecco, ${ }^{1}$ Martin Niedermeier, ${ }^{1}$ Gerhard Ruedl, ${ }^{1}$ Dagmar Walter, ${ }^{2}$ Regina Sterr, ${ }^{2}$ Hans Ebner, ${ }^{3}$ Wolfgang Schobersberger, ${ }^{4,5}$ Martin Burtscher ${ }^{1}$

To cite: Faulhaber M, Pocecco E, Niedermeier M, et al. Fall-related accidents among hikers in the Austrian Alps: a 9-year retrospective study. BMJ Open Sport \& Exercise Medicine 2017;3:e000304. doi:10.1136/ bmjsem-2017-000304

Accepted 3 November 2017

\section{CrossMark}

${ }^{1}$ Department of Sport Science, University of Innsbruck, Innsbruck, Austria

${ }^{2}$ Austrian Board of Alpine Safety, Innsbruck, Austria

${ }^{3}$ Austrian Alpine Police/Ministry of the Interior, Vienna, Austria ${ }^{4}$ Institute for Sports Medicine, Alpine Medicine and Health Tourism (ISAG), Tirol Kliniken $\mathrm{GmbH}$, Innsbruck, Austria ${ }^{5}$ Institute of Sports Medicine, Health Tourism and Leisure Sciences, Private University for Health Sciences, Medical Informatics and Technology (UMIT), Hall, Austria

Correspondence to Dr Martin Faulhaber; Martin. faulhaber@uibk.ac.at

\section{ABSTRACT}

Objective To analyse the circumstances of fatal and nonfatal mountain hiking accidents caused by falls.

Methods The study was designed as a retrospective analysis. Mountain hiking accidents caused by falls were documented during a 9-year period (2006-2014). After screening of all data for potential exclusion criteria the final sample size of 5368 accidents and 5665 victims was included into the analyses. Main outcome measures were details about accidents, victims, type of trail and surface. Results The annual number of accidents showed a continuous increase from 467 in 2006 to 700 in 2014. In total, $5.8 \%$ of all victims died during the 9 -year period. $75.3 \%$ of the hikers fell during descent and $80.9 \%$ of the victims had their accident on a marked hiking trail or small path. The sex ratio for non-fatal accidents was $55 \%$ female and $45 \%$ male; for fatal accidents the female-to-male ratio was $28 \%: 72 \%$. Mean age of all victims was $52.5 \pm 17.5$ years and victims of fatalities were about 5 years older compared with victims of non-fatal accidents $(57.5 \pm 16.5$ vs $52.2 \pm 17.5$ years, $P<0.01$ ).

Conclusion Descent is the most risky part for accidents caused by falls during mountain hiking. Male hikers are at greater risk for fatalities independent of age and this is associated with accidents occurring in pathless terrain. The death rate from falls was $6 \%$. We recommend a critical self-assessment of the individual capabilities and mountain hiking skills and adequate planning of the hiking tours for mountain hikers.

\section{INTRODUCTION}

Mountain sport activities are practised by an increasing number of people. Worldwide, an annual sum of 100 million high-altitude tourists was assumed and the number of tourists visiting altitudes above $2000 \mathrm{~m}$ in the Alps was estimated at about 40 million people per year. ${ }^{1}$ Mountain hiking is the most popular mountain sport activity in the Austrian Alps during the summer season attracting several million hikers each year including young and old people with and without pre-existing medical conditions. ${ }^{23}$ There is no reported precise definition of mountain hiking in the scientific literature.

\section{What are the new findings?}

- About $75 \%$ of falls during mountain hiking occur during descent. The death rate from falls is $6 \%$.

- Among fall-related fatalities about $72 \%$ are male and about $28 \%$ are female.

- Hikers over the age of 50 years are over-represented among non-fatal and fatal fall-related accidents.

How might it impact on clinical practice in the near future?

Mountain hikers should be informed on the following issues:

- The descent is a risky part for falls during mountain hiking.

- Accidents predominantly happen in good weather with clear trail conditions; internal risk factors play an important role.

For the present paper, mountain hiking is defined following the Tyrol Declaration on Best Practice in Mountain Sports as walking in a mountainous environment predominantly on marked trails and paths. ${ }^{4}$ Mountain hiking can require to cross boulder or snow fields or to climb in rocky terrain up to UIAA (International Climbing and Mountaineering Federation) grade 1 over short distances. Mountain hiking does not include passing glaciers or rock climbing in a rope party. From a physiological point of view, mountain hiking is generally characterised as a longlasting activity including large muscle mass with predominantly moderate intensity which is considered beneficial for health. ${ }^{6}$ Furthermore, positive effects of mountain hiking on psychological parameters have been reported, ${ }^{7}$ and the exposure to moderate altitudes may add specific health benefits even in vacationers with pre-existing chronic diseases. ${ }^{8}$ Therefore, mountain hiking can be 
recommended as suitable for health prevention also for elderly persons. ${ }^{9}$

The other side of the undoubtedly positive health effects of mountain sports activities, however, is the risk of accidents, emergencies, and even fatalities. The majority of scientific studies in mountain sports during the winter season focused on mortality and injury rates during alpine skiing ${ }^{10-14}$ and related risk factors ${ }^{10}{ }^{15}$ or on avalanche accidents. ${ }^{16}$ Most evaluations in mountain sports during the summer season concentrated on climbing or mountaineering accidents; ${ }^{18-21}$ however, specific data on mountain hiking accidents are scarce. Burtscher et al estimated a death rate of about 4 deaths per 100000 hikers per year during mountain hiking in Austria and identified risk factors for cardiovascular emergencies and sudden cardiac deaths. ${ }^{2}{ }^{22}$ However, about $45 \%$ of all fatal and non-fatal accidents during mountain hiking are caused by falls ${ }^{23}$ and this type of accidents and victims has not been analysed in detail yet.

According to the four-step sequence of injury prevention research, ${ }^{24}$ knowledge on the specific accident circumstances would be an important prerequisite to develop evidence-based preventive measures for mountain hikers and to improve safety in this popular sport. Therefore, the goal of the present study was to examine the circumstances of fatal and non-fatal mountain hiking accidents caused by falls and the characteristics of the victims with special focus on sex and age-specific differences.

\section{METHODS}

\section{General study design}

The present study was designed as a retrospective analysis of documented falls in mountain hikers during a 9-year period (2006-2014).

\section{Data collection and primary data source}

The primary data source was the data base for accidents and emergencies in the mountains of the Austrian Alpine Police (part of the Austrian Ministry of the Interior). Instructed staff of the Austrian Alpine Police continuously recorded details of accidents and emergencies during activities in the Austrian mountains during their routine work using standardised software forms. During the summer season, this procedure included nearly all accidents and emergencies with an emergency call via emergency call centre or the local mountain rescue service and all fatalities that occurred in the mountains. In most cases, information was received by telephone interview with the victim and/ or a person at the accident scene. In a few cases (ie, fatal accidents), information was gained by onsite inspection by staff of the Austrian Alpine Police.

The following details of each accident were entered in the database: categorised type of activity during which the accident occurred (eg, 'mountain hiking', 'alpine skiing', and so on), the location of the accident (federal province, community, mountain and route, and approximated altitude), weather conditions at the time of the accident (eg, sunny, overcast sky, foggy), the number of involved persons/victims and a short description of the accident's sequence of events. The following details for each victim were recorded: sex, age, nationality, membership in an alpine club ('yes' or 'no'), alcohol intake at the day of the accident ('yes' or 'no'), terrestrial rescue and/ or rescue by helicopter, degree of injury ('unharmed', 'slightly injured', 'seriously or life-threatening injured' or 'dead'). It was registered if the victim had the accident during the ascent or descent (if possible) and information to the type of trail ('drive or forest way', 'marked hiking trail or a small path', 'pathless terrain', 'others') and the surface ('grass', 'rocks/rubble', 'snow or ice' or 'others') was recorded. Additionally, the injury locations were noted according to Burtscher et al: polytrauma/ multiple injury locations, head, shoulder/back, chest/ abdomen, arm/hand, hip/pelvis, thigh, knee, lower leg, ankle/foot. ${ }^{25}$

\section{Data transfer}

The Austrian Board of Alpine Safety had access to the database of the Austrian Alpine Police, and the Austrian Alpine Police has approved to use the anonymised data for analyses. For the present study, the Austrian Board of Alpine Safety provided a data set including all recorded accidents (non-fatal and fatal), which were categorised to the activity 'hiking/mountaineering' in the Austrian Alps during the summer seasons (1 May to 31 October of each year) 2006-2014 to the Department of Sport Science (University of Innsbruck, Austria) for data analysis. Thereby, a data set including 5680 accidents comprised the primary data source.

\section{Data screening and data selection}

In a first step, all accidents were screened by three authors (MF, EP and MN) for potential exclusion criteria. Exclusion criteria were: (A) the type of activity at the time of the accident did not meet the definition of mountain hiking mentioned above (activity-based exclusion, eg, high-altitude mountaineering or mushroom collection), and (B) the accident was not caused by a fall or the fall was a consequence of another event (circumstance-based exclusion, eg, a fall as a consequence of a heart attack). Thereby, $312(5.5 \%)$ accidents were excluded from the subsequent statistical data analyses resulting in the final sample size of 5368 accidents including 5665 victims. Table 1 shows the details of the reasons for exclusion.

\section{Statistics}

SPSS software (V.24, IBM) was used to run statistical analyses. Descriptive data analysis of the selected accidents was conducted to characterise the victims and the circumstances of the accidents. Results are presented as means \pm SD or frequencies (percentage) as appropriate. Reduced sample sizes, caused by partially incomplete data sets, are indicated. Comparisons between subgroups (eg, female vs male) were performed by $\chi^{2}$ tests (nominal scaled variables) or independent t-test (continuous 
Table 1 Details on excluded cases $(n=312)$. Values are absolute and relative (percentage of all excluded cases) frequencies

\begin{tabular}{|c|c|}
\hline Reason for exclusion & Number of cases \\
\hline \multicolumn{2}{|c|}{$\begin{array}{l}\text { Activity-based exclusion (activity at the time of the accident } \\
\text { not defined as hiking) }\end{array}$} \\
\hline \multicolumn{2}{|l|}{ Other mountain sport activity } \\
\hline High-altitude mountaineering (glacier) & $67(21.5 \%)$ \\
\hline $\begin{array}{l}\text { Climbing or fixed-rope climbing (via } \\
\text { ferrata) }\end{array}$ & $14(4.5 \%)$ \\
\hline Mountain running & $8(2.6 \%)$ \\
\hline Geocaching & $4(1.3 \%)$ \\
\hline Mushroom/berry collectors, and so on & $71(22.8 \%)$ \\
\hline $\begin{array}{l}\text { Occupational activity (eg, professional } \\
\text { mountain guides) }\end{array}$ & $19(6.1 \%)$ \\
\hline Excursions of schools or youth groups & $13(4.2 \%)$ \\
\hline $\begin{array}{l}\text { Other activity: playing children, } \\
\text { accidents in a hut, and so on }\end{array}$ & $65(20.8 \%)$ \\
\hline \multicolumn{2}{|c|}{$\begin{array}{l}\text { Circumstance-based exclusion (cause of the accident was } \\
\text { not defined as a fall) }\end{array}$} \\
\hline $\begin{array}{l}\text { Accident was not a fall (eg, rescue } \\
\text { after getting lost, exhaustion) }\end{array}$ & $28(9.0 \%)$ \\
\hline $\begin{array}{l}\text { Fall was caused by an external } \\
\text { reason (eg, animal attack, } \\
\text { cardiovascular or metabolic event, } \\
\text { rock fall) }\end{array}$ & $23(7.4 \%)$ \\
\hline
\end{tabular}

variables). $\mathrm{P}$ values $<0.05$ were considered to indicate statistical significance.

\section{RESULTS}

\section{Characteristics of accidents}

Out of the nine federal provinces of Austria, most of the accidents occurred in Tyrol $(47.9 \%)$, followed by Vorarlberg (14.9\%), Salzburg (9.7\%), Upper Austria $(8.8 \%)$, Styria $(7.6 \%)$, Carinthia $(5.6 \%)$ and Lower Austria (5.6\%), and Burgenland $(0 \%)$ and Vienna $(0 \%)$. The annual number of accidents showed a continuous increase from 467 in 2006 to 700 in 2014 (see figure 1). The altitude of the accidents ranged from 254 to $3200 \mathrm{~m}$ $(1667 \pm 557 \mathrm{~m})$. With respect to different altitude zones, the frequency of accidents showed the following distribution: $656(13.2 \%)$ below $1000 \mathrm{~m}, 2857(57.6 \%)$ at $1000-1999 \mathrm{~m}, 1419(28.6 \%)$ at $2000-2999 \mathrm{~m}$ and 32 $(0.6 \%)$ at $3000 \mathrm{~m}$ or above $(\mathrm{n}=4964)$. Emergency calls were predominantly made by mobile phone $(77.1 \%)$. Up to $4.1 \%$ (218) of the accidents occurred in hikers guided by a certified mountain guide, a hiking guide or a person with a comparable official education. For 90\% (4689 out of 5209) of the accidents, good weather conditions, defined as sunny or clouded sky without precipitation, fog, darkness or other unfavourable conditions, were recorded. A total of $5120(95.4 \%)$ accidents were caused by falls with one person involved, followed by $215(4.0 \%)$

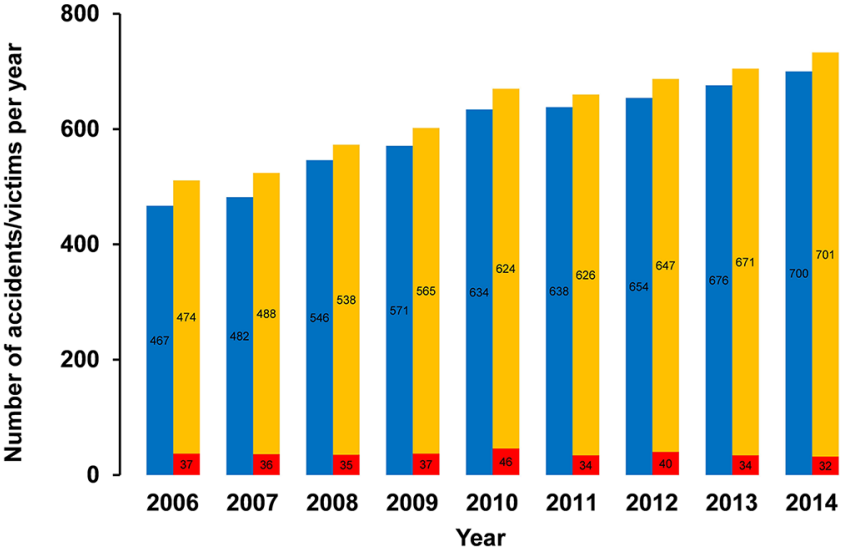

Figure 1 Annual number of accidents (blue columns) and victims separated for fatal (red columns) and non-fatal (yellow columns) outcomes during the 9-year period. Values are absolute frequencies.

accidents with two victims and $33(0.6 \%)$ accidents with more than two victims.

\section{Characteristics of accident victims}

In accordance to the annual number of accidents, the number of victims continuously increased from 2006 to 2014. In total, 331 (5.8\%) victims died during the 9-year period with a relatively stable absolute number of fatalities per year (figure 1). This development resulted in a declining mortality index (proportion of deaths/accident victims) from $7.2 \%$ in 2006 to $4.4 \%$ in 2014 . Among the non-fatally injured persons $(n=5334), 1720(32.2 \%)$ were unharmed or slightly injured, 2424 (45.4\%) were seriously or life-threatening injured and 1190 (22.3\%) were injured to an unknown degree. Victims were predominantly from Germany $(46.7 \%)$, Austria $(40.7 \%)$ and Benelux countries $(4.8 \%)(n=5632)$. Reported alcohol intake at the day of the accident was recorded in $1.7 \%$ of the victims $(n=5260)$ with no significant difference between non-fatally and fatally injured persons.

In total, $75.3 \%$ of hikers fell during descent, $20.0 \%$ during ascent and $4.7 \%$ during other activities that could not be defined as ascent or descent, for example, level walking $(\mathrm{n}=5517)$. The majority of hikers had their accident on a marked hiking trail or small path $(80.9 \%)$, $14.5 \%$ in pathless terrain, $3.6 \%$ on a drive or forest way and $1.1 \%$ other conditions $(n=5615)$. Comparing non-fatal versus fatal events, a shift in proportions from drive or forest way $(3.7 \%$ vs $0.6 \%)$ and marked hiking trail or small path $(82.0 \%$ vs $62.5 \%)$ to pathless terrain $(13.2 \%$ vs $35.0 \%)$ could be observed $(\mathrm{P}<0.01, \mathrm{n}=5615)$. Rocks or rubble were the most frequent surfaces where hikers had an accident $(60.8 \%)$, followed by grass $(13.9 \%)$, snow or ice $(6.2 \%)$ and other surfaces $(19.0 \%)$ $(n=5457)$. Concerning the most frequent injury locations among the fatalities $(n=309), 44.3 \%$ of injuries affected multiple body parts (polytraumatic injuries) and $43.4 \%$ the head. The pattern of injury locations in non-fatal accidents $(n=5055)$ was significantly different compared 
Table 2 Circumstances of falls separated for female and male victims. Values are absolute (relative) frequencies. $P$ values refer to differences between women and men by $\chi^{2}$ test

\begin{tabular}{lcccc}
\hline & $\begin{array}{l}\text { Female } \\
\text { victims }\end{array}$ & Male victims & P value & n \\
\hline Activity & & & & \\
\hline Ascent & $537(18.3)$ & $569(22.1)$ & $<0.01$ & 5510 \\
Descent & $2268(77.1)$ & $1879(73.1)$ & & \\
Other activity & $135(4.6)$ & $122(4.7)$ & & \\
Alcohol intake & $15(0.5)$ & $82(3.4)$ & $<0.01$ & 5254 \\
Type of terrain & & & & \\
$\begin{array}{l}\text { Drive or forest } \\
\text { way }\end{array}$ & $132(4.4)$ & $65(2.5)$ & $<0.01$ & 5608 \\
$\begin{array}{l}\text { Marked hiking } \\
\text { trail or path }\end{array}$ & $2535(84.6)$ & $2003(76.7)$ & & \\
$\begin{array}{l}\text { Pathless } \\
\text { terrain }\end{array}$ & $301(10.0)$ & $511(19.6)$ & & \\
$\begin{array}{l}\text { Other } \\
\text { conditions }\end{array}$ & $30(1.0)$ & $31(1.2)$ & & \\
\hline $\begin{array}{l}\text { Surface } \\
\text { Grass }\end{array}$ & $398(13.8)$ & $362(14.1)$ & $<0.01$ & 5450 \\
$\begin{array}{l}\text { Rocks or } \\
\text { rubble }\end{array}$ & $1714(51.7)$ & $1602(48.3)$ & & \\
$\begin{array}{l}\text { Snow or ice } \\
\text { Other surface }\end{array}$ & $640(22.1)$ & $394(15.4)$ & & \\
\hline
\end{tabular}

with fatalities: $37.8 \%$ ankle and foot, $12.8 \%$ head, $10.0 \%$ lower leg and $38.8 \%$ other locations $(\mathrm{P}<0.01)$.

Sex-specific characteristics

Out of 5658 victims, 3017 (53.3\%) were female and 2641 $(46.7 \%)$ were male . There were sex-specific differences between non-fatal and fatal accidents $(\mathrm{P}<0.01)$ : Within non-fatal accidents 2925 women $(54.9 \%)$ and 2402 men $(45.1 \%)$ were represented $(n=5327)$ whereas men were predominant compared with women in accidents with fatal outcome (239 (72.2\%) vs $92(27.8 \%), \mathrm{n}=331)$. Circumstances of falls separated for female and male victims are shown in table 2. Injury locations did not differ between sexes in fatal accidents; however, among non-fatal accidents injury locations significantly differed in female compared with male victims (figure 2).

Age-specific characteristics

Mean age of all victims was $52.5 \pm 17.5$ years $(n=5632)$ and victims of fatalities were about 5 years older compared with victims of non-fatal accidents $(57.5 \pm 16.5$ vs $52.2 \pm 17.5$ years, $\mathrm{P}<0.01, \mathrm{n}=5632$ ). Figure 3 shows an age and sex-dependent distribution of accident victims across fatal and non-fatal accidents.

\section{DISCUSSION}

This study extends the knowledge on fall-related accidents in mountain hikers. The main results include: (A)

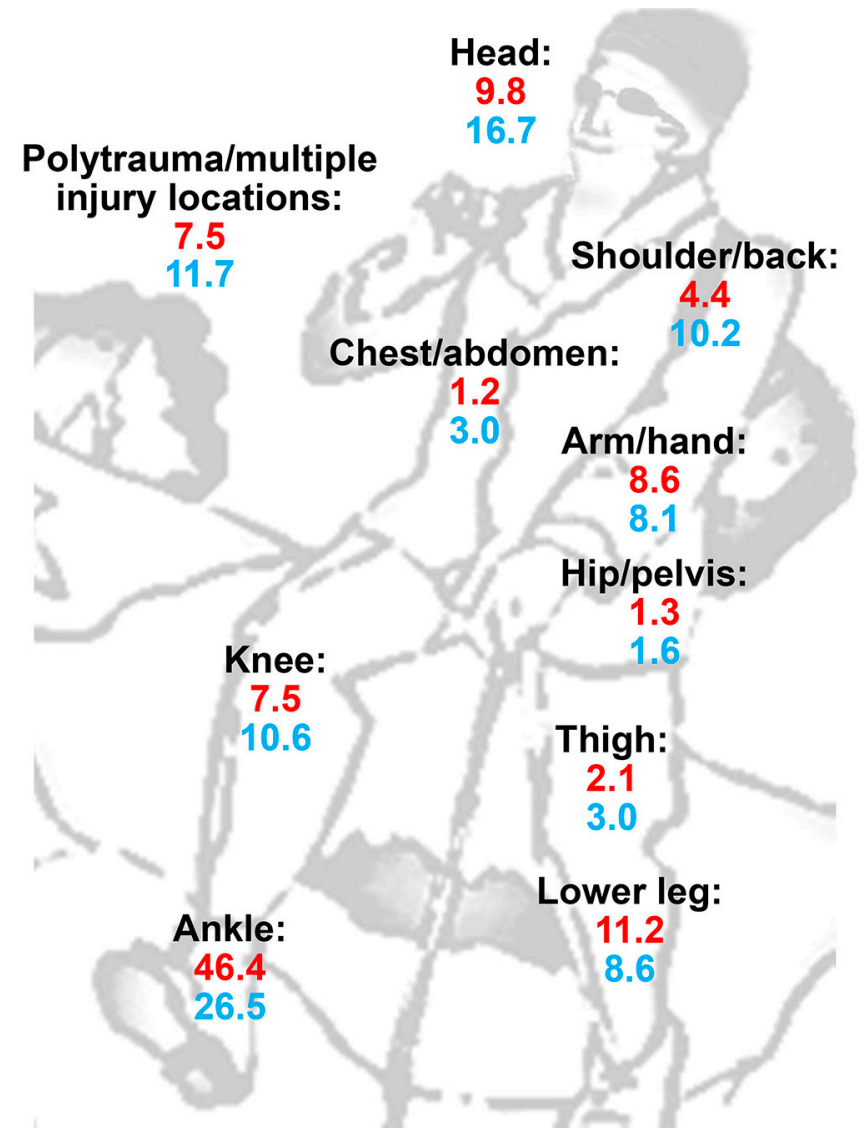

Figure 2 Percentages of injury locations for non-fatal fall-related accidents in female (red) versus male (blue) mountain hikers. There were significant differences $(P<0.01)$ in the injury locations between women $(n=2825)$ and men $(n=2223)$.

an increase in the number of non-fatal injured victims and a relatively stable number of fatalities from 2006 to 2014, (B) a predominance of falls on rocks or rubble and during descent, and (C) sex and age-specific characteristics in the circumstances of falls.

Theincrease in non-fatalities (about 50 \%) from 2006 to 2014, recorded by the Austrian Alpine Police, could be caused by the increasing popularity of mountain hiking in the Austrian Alps. Although the exact number of mountain hikers and its development remains elusive, ${ }^{26}$ there is evidence of a growing popularity during the last two decades. The number of members of the Austrian and the German Alpine Association (OeAV and DAV, respectively) may be considered as a surrogate for the numerical development in mountain sport active individuals in the Austrian Alps. Both societies showed an increase in members of $49 \%$ (OeAV) and 44\% (DAV) from 2006 to $2014 .^{27} 28$ This development can be interpreted as an increase in the population at risk for mountain sport accidents to the same extent as the number of accidents increased during this period. However, the present data include only accidents captured via an emergency call which was done in $77.1 \%$ by mobile phone. It might be possible that improved mobile phone network 

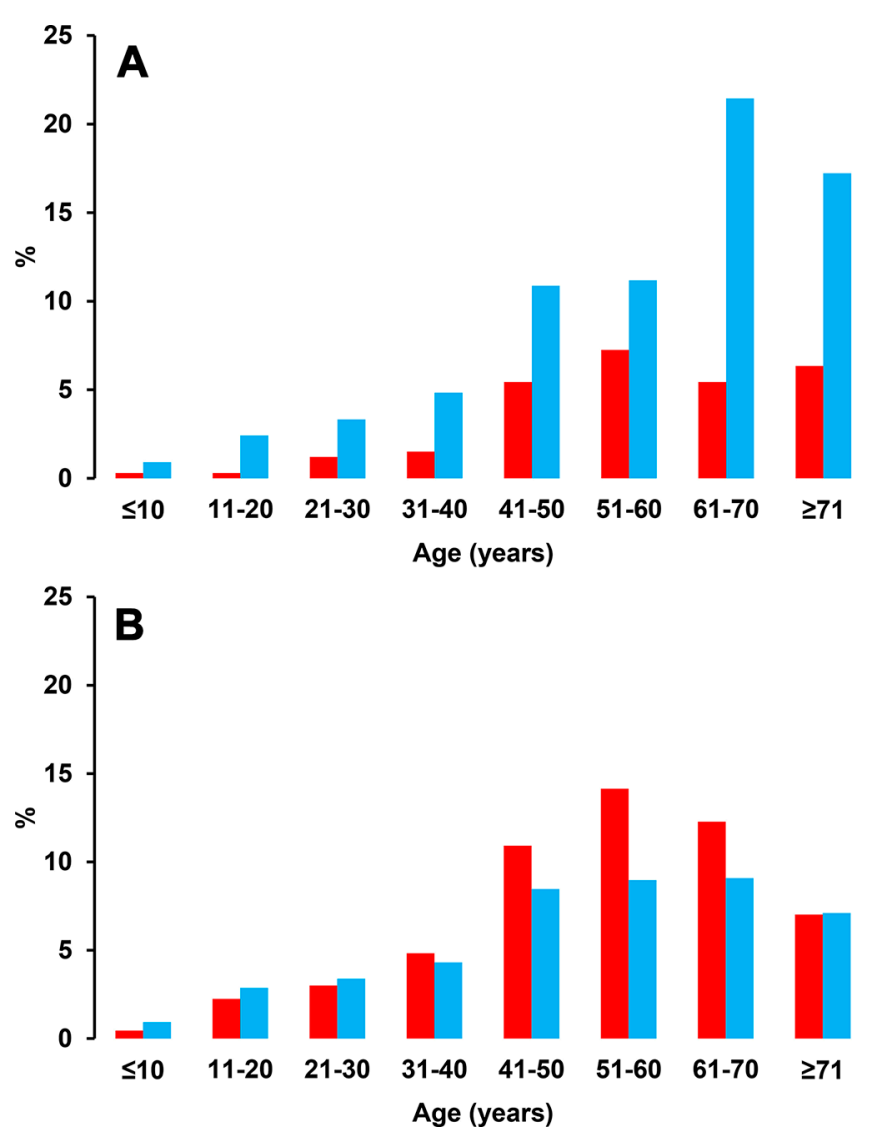

Figure 3 Age and sex-specific distribution of victims of fatal (A) and non-fatal accidents (B). Red columns=women, blue columns=men. Values are relative frequencies and refer to the proportion within fatalities $(n=331)$ and within non-fatalities $(n=5295)$, respectively.

availability in mountainous regions has facilitated emergency calls and has contributed to the higher number of recorded non-fatal accidents. Nonetheless, the relatively stable number of fatalities does not follow the trend in non-fatal events and is in line with previous reports. ${ }^{21}$ The calculated mortality index decreased by about $40 \%$ from 2006 to 2014 and the actual value is comparable to data reported from France for hiking on paths (4\%) but lower compared with hiking off paths or mountaineering $(10 \%-15 \%) \cdot{ }^{26}$ This development may indicate that mountain hiking became safer during the evaluated period with respect to fatal falls.

The observation that most accidents occurred below $3000 \mathrm{~m}$ on marked hiking trails or small paths and in good weather conditions is likely due to the fact that this is the preferred environment of the majority of hikers in the Alps. The vast majority of the accidents happened when hiking on trails or paths with rocks or rubble and during the descent. Although the reasons and mechanisms cannot be elucidated by the present data, it can be speculated that factors like the unfamiliar trail surfaces in a mountainous environment and the muscular load of downhill walking may play a role. Since many hiking trips start with uphill walking followed by the descent, a general muscular fatigue may be additionally involved. ${ }^{29}{ }^{30}$ Furthermore, alcohol and/or medication intake, both common among mountain hikers, can increase risk of falling. ${ }^{31}{ }^{32}$ Extended snow fields can challenge mountain hikers especially at the beginning of the summer season and usually become less frequent in the course of the summer. Although the proportion of falls on snow and ice seems to be relatively low (6.2\%), the absolute number of about 40 accidents per year cannot be neglected. Since most of the mountain hikers are not skilled in passing hard snow without specific equipment, the use of light crampons or spikes may be effective to prevent such accidents.

The sex-specific differences seem to be of specific interest for practical application because women were more frequent among non-fatal injured victims but under-represented among fatalities compared with men. Although a direct calculation of sex-specific risks is not possible, the following comparison can help interpret the sex-specific differences. Assuming a distribution of $39.8 \%$ women and $60.2 \%$ men in the general population of hikers as a reference for hikers without falls, ${ }^{3}$ odd ratios (OR) for female compared with male hikers can be calculated: OR 1.73 for falls in general, OR 1.84 for non-fatal falls and OR 0.58 for fatal falls. The higher risk for non-fatalities in women is in contrast to the results of evaluations in elderly populations in nursing homes and hospitals. ${ }^{33}$ The higher risk for fatal falls in male compared with female hikers may be due to the fact that male hikers have more accidents in pathless terrain and show a higher risk-taking behaviour compared with female hikers. ${ }^{34}$

At least three limitations have to be addressed. First, the database of the Austrian Alpine Police includes only accidents followed by an emergency call. This results in a selected sample with more severe injuries and it is very likely that falls with slight injuries and in conditions where victims were able to descend on their own were not included. As a consequence, the real number of accidents, especially involving slightly injured persons, may be underestimated. Second, information of accidents and victims was recorded during routine work by staff of the Austrian Alpine Police. On the one hand, this procedure ensures a highly standardised data input by trained staff. On the other hand, information has to be limited for organisational reasons. Third, the population under risk in mountain hiking cannot be quantified with sufficient accuracy and frequency as well as duration of exposure remains unknown. Therefore, real risk calculations cannot be provided based on the present data.

In conclusion, falls are a relevant cause of fatal and non-fatal accidents in mountain hikers. Despite some limitations, practical recommendations for mountain hikers can be derived from the present data. Mountain hikers should be aware that the descent, associated with many hikers' unfamiliar eccentric muscular strain, is the most risky part of a mountain hiking tour for accidents caused by falls. An adequate tour planning with time reserves and regular 
breaks could probably reduce the risk of falls-especially in women and persons over 40 years of age.

In general, male hikers are at greater risk for fatalities independent of age but associated with accidents in pathless terrain. A critical self-assessment of the individual capabilities and mountain hiking skills as well as adequate selection and planning of the hiking tours seem to be important for mountain hikers. Since the present study can only provide information on accidents and circumstances, future research should focus on the identification of risk factors for falls in mountain hikers as a next step in accident prevention. ${ }^{24}$ Therefore, knowledge on the specific internal (eg, fatigue, fitness level, experience) and external circumstances (eg, underground, altitude) of falls during mountain hiking is of utmost importance to identify risk factors and to develop evidence-based preventive measures.

Contributors MF designed the study, conducted data analysis and interpretation, and wrote the draft of the manuscript. EP and MN contributed to data analysis and drafting of the manuscript. GR and WS contributed to interpretation of the data and review of the manuscript. DW and RS contributed to data acquisition and data transfer. MB contributed to designing the study, interpretation of the data and review of the manuscript. MF is the guarantor.

Funding MF has received research grants from the Austrian Science Fund (FWF).

Competing interests MF has received research grants from the Austrian Science Fund (FWF).

Patient consent Detail has been removed from this case description/these case descriptions to ensure anonymity. The editors and reviewers have seen the detailed information available and are satisfied that the information backs up the case the authors are making.

Ethics approval Board for Ethical Questions in Science of the University of Innsbruck, Austria (Certificate No 36/2015).

Provenance and peer review Not commissioned; internally peer reviewed.

Open Access This is an Open Access article distributed in accordance with the Creative Commons Attribution Non Commercial (CC BY-NC 4.0) license, which permits others to distribute, remix, adapt, build upon this work non-commercially, and license their derivative works on different terms, provided the original work is properly cited and the use is non-commercial. See: http://creativecommons.org/ licenses/by-nc/4.0/

(C) Article author(s) (or their employer(s) unless otherwise stated in the text of the article) 2017. All rights reserved. No commercial use is permitted unless otherwise expressly granted.

\section{REFERENCES}

1. Burtscher M, Bachmann O, Hatzl T, et al. Cardiopulmonary and metabolic responses in healthy elderly humans during a 1 -week hiking programme at high altitude. Eur J Appl Physiol 2001;84:379-86.

2. Burtscher M, Pachinger O, Schocke MF, et al. Risk factor profile for sudden cardiac death during mountain hiking. Int J Sports Med 2007;28:621-4.

3. Faulhaber M, Flatz M, Gatterer H, et al. Prevalence of cardiovascular diseases among alpine skiers and hikers in the Austrian Alps. High Alt Med Biol 2007;8:245-52.

4. Austrian Alpine Association. Tyrol Declaration to best practice in mountain Sports. 2002 https://theuiaa.org/declarations/tyroldeclaration (accessed 27 Sep 2017).

5. Niedermeier M, Hartl A, Kopp M. Prevalence of mental health problems and factors associated with psychological distress in mountain exercisers: a cross-sectional study in Austria. Front Psychol 2017;8:1237.

6. Powell KE, Paluch AE, Blair SN. Physical activity for health: What kind? How much? How intense? On top of what? Annu Rev Public Health 2011;32:349-65.
7. Niedermeier M, Einwanger J, Hartl A, et al. Affective responses in mountain hiking-a randomized crossover trial focusing on differences between indoor and outdoor activity. PLoS One 2017;12:e0177719.

8. Schobersberger W, Leichtfried V, Mueck-Weymann M, et al. Austrian Moderate Altitude Studies (AMAS): benefits of exposure to moderate altitudes (1,500-2,500 m). Sleep Breath 2010;14:201-7.

9. Gatterer H, Raab C, Pramsohler S, et al. Effect of weekly hiking on cardiovascular risk factors in the elderly. Z Gerontol Geriatr 2015;48:150-3.

10. Burtscher M, Pachinger O, Mittleman MA, et al. Prior myocardial infarction is the major risk factor associated with sudden cardiac death during downhill skiing. Int J Sports Med 2000;21:613-5.

11. Xiang $\mathrm{H}$, Stallones $\mathrm{L}$. Deaths associated with snow skiing in Colorado 1980-1981 to 2000-2001 ski seasons. Injury 2003;34:892-6.

12. Ruedl $\mathrm{G}$, Bilek $\mathrm{H}$, Ebner $\mathrm{H}$, et al. Fatalities on Austrian ski slopes during a 5-year period. Wilderness Environ Med 2011;22:326-8.

13. Koehle MS, Lloyd-Smith R, Taunton JE. Alpine ski injuries and their prevention. Sports Med 2002;32:785-93.

14. Brooks MA, Evans MD, Rivara FP. Evaluation of skiing and snowboarding injuries sustained in terrain parks versus traditional slopes. Inj Prev 2010;16:119-22.

15. Ruedl G, Webhofer M, Helle K, et al. Leg dominance is a risk factor for noncontact anterior cruciate ligament injuries in female recreational skiers. Am J Sports Med 2012;40:1269-73.

16. Rainer B, Frimmel C, Sumann G, et al. Correlation between avalanche emergencies and avalanche danger forecast in the alpine region of Tyrol. Eur J Emerg Med 2008;15:43-7.

17. Boyd J, Haegeli P, Abu-Laban RB, et al. Patterns of death among avalanche fatalities: a 21-year review. CMAJ 2009;180:507-12.

18. Lack DA, Sheets AL, Entin JM, et al. Rock climbing rescues: causes, injuries, and trends in Boulder County, Colorado. Wilderness Environ Med 2012;23:223-30.

19. Schöffl V, Morrison A, Schwarz U, et al. Evaluation of injury and fatality risk in rock and ice climbing. Sports Med 2010;40:657-79.

20. Marsigny B, Lecoq-Jammes F, Cauchy E. Medical mountain rescue in the Mont-Blanc massif. Wilderness Environ Med 1999;10:152-6.

21. Lischke V, Byhahn $\mathrm{C}$, Westphal $\mathrm{K}$, et al. Mountaineering accidents in the European Alps: have the numbers increased in recent years? Wilderness Environ Med 2001;12:74-80.

22. Burtscher M, Ponchia A. The risk of cardiovascular events during leisure time activities at altitude. Prog Cardiovasc Dis 2010;52:507-11.

23. Faulhaber M, Ruedl G, Burtscher M. Unfälle beim bergwandern, auf hochtourenund beim klettern. FTR 2012;4:171-5.

24. Bahr R, Krosshaug T. Understanding injury mechanisms: a key component of preventing injuries in sport. Br J Sports Med 2005;39:324-9.

25. Burtscher M, Gatterer H, Flatz M, et al. Effects of modern ski equipment on the overall injury rate and the pattern of injury location in Alpine skiing. Clin J Sport Med 2008;18:355-7.

26. Soulé B, Lefèvre B, Boutroy $E$. The dangerousness of mountain recreation: a quantitative overview of fatal and non-fatal accidents in France. Eur J Sport Sci 2017;17:931-9.

27. Austrian Alpine Association (Österreichischer Alpenverein). Jahresbericht 2016, 2017. http://www.alpenverein.at/portal wAssets/docs/service/JB_2016_ebook.pdf (accessed 27 Sep 2017).

28. German Alpine Association (Deutscher Alpenverein). Jahresbericht 2016, 2017. https://www.alpenverein.de/chameleon/public/ 03cb087f-9b7d-45cf-dcbf-f0144af2f9d1/Jahresbericht-2016Broschuere OL 28412.pdf (accessed 27 Sep 2017).

29. Kingsley MI, Kilduff LP, McEneny J, et al. Phosphatidylserine supplementation and recovery following downhill running. Med Sci Sports Exerc 2006;38:1617-25.

30. Gatterer H, Schenk K, Wille M, et al. Race performance and exercise intensity of male amateur mountain runners during a multistage mountain marathon competition are not dependent on muscle strength loss or cardiorespiratory fitness. J Strength Cond Res 2013;27:2149-56.

31. Burtscher M, Pühringer R, Werner I, et al. Predictors of falls in downhill skiing and snowboarding. In: Müller E, Lindinger S, Stöggl T, eds. Science and Skiing IV. Aachen: Meyer \& Meyer Sport, 2009

32. Kool B, Ameratunga S, Robinson E. Association between prescription medications and falls at home among young and middle-aged adults. Inj Prev 2012;18:200-3.

33. Deandrea S, Bravi F, Turati F, et al. Risk factors for falls in older people in nursing homes and hospitals. A systematic review and meta-analysis. Arch Gerontol Geriatr 2013;56:407-15. 
34. Ruedl G, Abart M, Ledochowski L, et al. Self reported risk taking and risk compensation in skiers and snowboarders are associated with

sensation seeking. Accid Anal Prev 2012;48:292-6. 